\title{
ANALISIS CUSTOMER SATISFACTION INDEX (CSI) TERHADAP KINERJA PEDAGANG SAYURAN DI PASAR TRADISIONAL KABUPATEN SUKOHARJO
}

\section{Analysis of Customer Satisfaction Index (CSI) on Traditional Market Merchant Performance In Sukoharjo District}

\author{
Ratih Dwi Kartikasari \\ Universitas Tunas Pembangunan \\ Jl. Balekambang Lor No.1 Banjarsari, Manahan, Surakarta \\ ratihkartika14@gmail.com
}

\begin{abstract}
Consumption of vegetables needs to be done to fulfill daily nutrition. The traditional market is one of the retail markets that provides fresh vegetables and is easily found in various regions. Marketing mix is one of the marketing strategies applied by traders to find out and assess customer satisfaction. The purpose of this study is to determine consumer satisfaction in shopping for vegetables in traditional markets. The method used is the Customer Satisfaction Index (CSI) analysis. The research location is in Sukoharjo District with 60 respondents of traditional market vegetable consumers with quota sampling technique. Based on the results of the study note that the CSI value of all variables is $77 \%$, which means that respondents are satisfied with the performance of vegetable merchants in traditional markets in Sukoharjo Regency. The sequence of variables that gives the highest to lowest satisfaction according to consumers is the product, price, people, physical evidence, promotion, place, and process variables.
\end{abstract}

Keywords: Traditonal Market, Vegetable, CSI

\begin{abstract}
ABSTRAK
Konsumsi sayur yang cukup perlu dilakukan untuk pemenuhan gizi sehari-hari. Pasar tradisional merupakan salah satu pasar retail yang menyediakan sayuran segar dan mudah ditemui di berbagai wilayah. Bauran pemasaran merupakan salah satu strategi pemasaran yang diterapkan peagang untuk mengetahui dan menilai kepuasan konsumen. Tujuan penelitian ini adalah menentukan kepuasan konsumen dalam berbelanja sayuran di pasar tradisional. Metode yang digunakan adalah analisis Customer Satisfaction Index (CSI). Lokasi penelitian berada di Kabupaten Sukoharjo dengan jumlah responden 60 konsumen sayuran pasar tradisional dengan tekhnik quota sampling. Berdasarkan hasil penelitian diketahui nilai CSI seluruh variabel adalah $77 \%$ yang berarti responden puas dengan kinerja pedagang sayuran di pasar tradisional di Kabupaten Sukoharjo. Urutan variabel yang memberikan kepuasan tertinggi hingga terendah menurut konsumen adalah variabel product, price, people, phisically evidence, promotion, place, dan process.
\end{abstract}

Kata Kunci: Pasar tradisional, sayuran, CSI 



\section{PENDAHULUAN}

Salah satu kebutuhan dasar manusia yang harus terpenuhi kuantitas dan kualitasnya adalah pangan. Pangan yang baik berarti dapat memenuhi syarat aman, bermutu dan bergizi bagi masyarakat (UU No 18 tahun 2012). Makanan sehat tidak hanya dipenuhi dari nasi dan lauk pauk akan tetapi juga mencakup sayur dan buah. Konsumsi sayur dan buah perlu dilakukan setiap hari mengingat pentingnya manfaat kesehatan yang diperoleh karena sayur dan buah memiliki kandungan yang baik seperti vitamin, mineral, dan serat yang cukup tinggi (Baliwati et al., 2004; Pakaya,2014).

Terdapat perbedaan pola konsumsi sayur dan buah antara penduduk perkotaan dan pedesaan. Pada tahun 2016, penduduk pedesaan mengkonsumsi sayur dan buah lebih rendah dibandingkan dengan penduduk perkotaan. Sementara sebelum tahun 2015, terjadi pola konsumsi yang berbeda, dimana konsumsi sayur dan buah penduduk perkotaan lebih rendah dibandingkan dengan penduduk pedesaan. Konsumsi buah cenderung lebih tinggi bagi penduduk perkotaan sementara penduduk pedesaan lebih tuinggi mengkonsumsi sayur (BMKG, 2017).

Mubyarto (1989) menyatkan bahwa sebagian besar penduduk Indonesia hidup atau berprofesi pada sektor pertanian. Sayuran dapat ditemui di pasar baik tradisional maupun moderndengan jenis produsen yang berbeda. Meskipun pasar modern kian berkembang pesat, pasar tradisional masih menjadi primadona bagi beberapa pelanggannya. Bagi masyarakat pedesaan, keberadaan pusat pelayanan perekonomian memiliki peran yang sangat penting bagi kemajuan ekonomi dan perkembangan masyarakat (Kartikasari, 2018).

Persaingan yang semakin ketat menjadikan antar produsen berupaya untuk meninngkatkan kualitas produknya sehingga dapat diterima oleh pasar. Tidak hanya dari kualitas produk sayuran akan tetapi beberapa atribut dalam memasarkan sayuran perlu diperhatikan untuk menjaga minat dan kepuasan konsumen berbelanja. Kotler dan Keller (2009) menyatakan kepuasan sebagai perasaan senang atau kecewa yang muncul akibat membandingkan kinerja yang diperoleh dengan ekspektasi seseorang. Jika kinerja sesuai dengan ekspektasi maka akan muncul kepuasan, sementara jika kinerja tidak sesuai dengan ekspektasi maka akan muncul rasa kecewa. Kepuasan konsumen dapat menciptakan kesetiaan atau loyalitas konsumen kepada pelaku usaha yang memberikan kualitas pelayanan memuaskan (Tjiptono, 2008).

Khususnya bagi produsen pasar tradisional, mengetahui faktor yang dipertimbangkan konsumen dalam berbelanja sayur akan menjaga loyalitas konsumen dalam berbelanja di pasar tradisional (Ali, Purwanti, \& Hidayati, 2019). Hal ini penting karena produsen yang mengetahui faktor-faktor utama yang dipertimbangkan konsumen dalam berbelanja akan meningkatkan kualitas pelayanannya sehingga dapat menjaga keberlangsungan usaha produsen. Tjiptono dan Chandra (2005) mengungkapkan bahwa persepsi kualitas jasa dapat dirubah oleh pengguna dengan adanya penilaian kepuasan. Dengan demikian pedagang atau produsen dapat meningkatkan kepuasan pelanggan dengan memaksimumkan pengalaman pelanggan yang menyenangkan dan meminimumkan pengalaman pelanggan yang kurang menyenangkan (Al-Tit, 2015). Berdasarkan latar belakang diatas tujuan penelitian ini adalah menentukan tingkat kepuasan konsumen sayuran di pasar tradisional Kabupaten Sukoharjo.

\section{METODE PENELITIAN}

Metode dasar yang digunakan adalah deskriptif analitik. Lokasi penelitian berada di Kabupaten Sukoharjo dengan jumlah responden 60 konsumen sayuran pasar tradisional (Suryani dan Hendryadi, 2015). Penentuan jumlah 
responden menggunakan teknik quota sampling. Data yang digunakan adalah data primer dan sekunder. Penelitian ini menggunakan dua jenis skala Likert yang berbeda untuk pernyataan Tingkat Kepentingan (TKPT) konsumen dan Tingkat Kinerja (TKN) pedagang menurut konsumen di pasar tradisional. Pernyataan tingkat Kinerja Pedagang akan menggunakan jawaban "sangat tidak puas" untuk poin terendah (1) hingga "sangat puas" untuk poin tertinggi (5). Sedangkan tingkat kepentingan konsumen akan menggunakan jawaban "sangat tidak penting" untuk poin terendah (1) hingga "sangat penting" untuk poin tertinggi (5) (Sugiyono, 2012).

Metode analisis data yang digunakan adalah dengan Customer Satisfaction Index (CSI). Data atribut bauran pemasaran ditabulasi secara sederhana dan dianalisis dengan software Ms. Excel. Rumus perhitungan tingkat kepentingan setiap pertanyaan pada atribut bauran pemasaran menurut Sugiyono (2012) di pasar tradisional adalah:

1. Menentukan Mean Importance Score (MIS-i) atau Rerata Skor Kepentingan dan Mean Satisfaction Score (MSS-i) atau Rerata Skor Kepuasan.

MIS $-\mathrm{i}=\frac{\sum_{1=1}^{\mathrm{u}} Y !}{n} \quad$ MSS $-\mathrm{i}=\frac{\sum_{1=1}^{\mathrm{H}} X i}{n}$

Keterangan:

$\mathrm{n} \quad$ : jumlah responden

$\mathrm{Xi}$ : nilai tingkat kinerja pedagang menurut konsumen

$\mathrm{Yi}$ : nilai tingkat kepentingan konsumen

2. Menentukan Weight Factor (WF-i) atau Bobot Skor Kepentingan

$$
\mathrm{WF}-\mathrm{i}=\frac{M I S-1}{2^{\mathrm{MIS}}}
$$

3. Menentukan Weight Score (WS-i)

$$
\text { WS- } i=\text { MSS- } \mathrm{x} \text { WF- } \mathrm{i}
$$

4. Menentukan Weight Total (WT)

$\mathrm{WT}=\mathrm{WS} 1+\mathrm{WS} 2+\mathrm{WS} 3+\ldots \ldots .+$

WSn

5. Menghitung Satisfaction Index

$$
\mathrm{CSI}=\frac{\mathrm{WI}}{\mathrm{HS}} \times 100 \%
$$

Keterangan :

$\mathrm{WT}=$ skor total

$\mathrm{HS}=$ skala maksimum yang digunakan

Tingkat kepuasan konsumen dapat dilihat dari kriteria tingkat kepuasan konsumen. Kepuasan tertinggi akan dicapai bila Customer Satisfaction Index (CSI) dalam kriteria kepuasan konsumen menunjukkan rentang $100 \%$. Adapun kriteria kepuasan konsumen sebagai berikut:

Tabel 1. Kriteria Kepuasan Konsumen

\begin{tabular}{cc}
\hline Nilai CSI $(\%)$ & Keterangan \\
\hline $0.00 \leq \mathrm{n} \leq 20,99$ & SangatTidakPuas \\
$21.00 \leq \mathrm{n} \leq 40,99$ & TidakPuas \\
$41.00 \leq \mathrm{n} \leq 60,99$ & CukupPuas \\
$61.00 \leq \mathrm{n} \leq 80,99$ & Puas \\
$81.00 \leq \mathrm{n} \leq 100.00$ & SangatPuas \\
\hline
\end{tabular}

Sumber : Sugiyono, 2012

\section{HASIL DAN PEMBAHASAN}

Terdapat empat belas atribut yang terbagi ke dalam tujuh variabel dalam perhitungan Customer Satisfaction Index (CSI). Setiap atribut memiliki Weight Score berbeda-beda dan berpengaruh dalam perhitungan CSI setiap variabel.

Tabel 2. Analisis Perhitungan Nilai CSI Variabel Product

\begin{tabular}{ccccc} 
Atribut & & WF & MSS & WS \\
& & & & \\
& & $(3)=$ & & $(5)=$ \\
$(1)$ & $(2)$ & $(2) /$ total & $(4)$ & $(3 \times 4)$ \\
\hline Keragaman & 4,85 & 0,51 & 4,45 & 2,26 \\
Kesegaran & 4,70 & 0,49 & 4,42 & 2,17 \\
Total & 9,55 & & & 4,43 \\
Nilai CSI & & & & $89 \%$ \\
\hline
\end{tabular}

Sumber : Data primer, diolah (2019)

Atribut pada variabel product yang paling dianggap penting oleh konsumen adalah keragaman sayuran dengan nilai WS adalah 2,26. Jenis sayuran yang beragam menjadi daya tarik bagi konsumen untuk berbelanja. Mayoritas 
sayuran diolah dengan beberapa campuran bahan, sehingga semakin variatif jenis sayuran akan memudahkan konsumen untuk memilih. Dengan sayur yang beragam di satu tempat maka konsumen tidak membutuhkan tenaga untuk mencari di tempat lain sehingga memberikan dampak efisiensi waktu dan tenaga.

Produk yang segar juga menjadi pertimbagan penting bagi konsumen dengan nilai WS sebesar 2,17 dimana hal ini sesuai dengan penelitian Ghezelbash (2017) yang menyatakan bahwa kualitas makanan berpengaruh signifikan dan positif terhadap minat beli. Menawarkan produk yang segar termasuk salah satu aspek untuk menjaga kualitas produk sesuai pendapat Arifin dan Yusuf (2016) bahwa kualitas adalah keunggulan yang dimiliki produk dan memberikan pandangan tersendiri bagi konsumen. Jadwal pengiriman sayur di pasar tradisional adalah pada dini hari, sehingga konsumen yang berbelanja pada pagi hari akan mudah mendapati sayur segar dan beragam. Semakin siang maka kualitas sayuran akan menurun karenapedagang tidak menggunakan pendingin untuk produk sayurnya. Nilai CSI dari variabel productadalah $89 \%$ yang tergolong sangat puas.

Tabel 3. AnalisisPerhitunganNilai CSI Variabel Price

\begin{tabular}{|c|c|c|c|c|}
\hline Atribut & & WF & MSS & WS \\
\hline (1) & (2) & $\begin{array}{c}(3)= \\
(2) / \text { total }\end{array}$ & (4) & $\begin{array}{l}(5)= \\
(3 \times 4)\end{array}$ \\
\hline $\begin{array}{l}\text { Dapat } \\
\text { ditawar }\end{array}$ & 3,67 & 0,52 & 4,30 & 2,23 \\
\hline $\begin{array}{l}\text { Lebih } \\
\text { murah }\end{array}$ & 3,42 & 0,48 & 3,95 & 1,91 \\
\hline Total & 7,08 & & & 4,13 \\
\hline Nilai CSI & & & & $83 \%$ \\
\hline
\end{tabular}

Salah satu indikator produk dikatakan mahal apabila memiliki kualitas dan manfaat yang sama daripada produk sejenis dengan harga yang lebih murah. Konsumen pasar tradisional Kabupaten Sukoharjo dapat melakukan transaksi yang diawali dengan tawar-menawar antara pedagang dan pembeli sampai diperoleh kesepakatan harga. Nilai WS atribut harga yang dapat ditawar konsumen adalah 2,23 lebih tinggi dari atribut harga yang lebih murah yaitu 1,91 . Harga produk sayuran di pasar tradisional dimana konsumen sering berbelanja dianggap tidak lebih murah dari pada pasar lain. Rata-rata harga yang ditawarkan oleh pedagang adalah sama.

Kepuasan konsumen akan muncul ketika berhasil menawar produk yang ditawarkan oleh produsen meskipun denan selisih yang sedikit. Kepuasan batin yang berpengaruh terhadap psikologi konsumen menjadikan konsumen senang untuk berbelanja di pasar tradisional. Pedagang pasar tradisional menjual produknya dengan jujur dimana tidak curang dan menjual barang setara antara harga dan kualitasnya. Hal ini di dukung oleh penelitian Musayana et al., (2017) yang menyatakan bahwa pedagang yang jujur yaitu pedagang yang berkata atau memberikan informasi sesuai dengan kenyataan, jujur dalam menjelaskan kondisi barang dan jujur dalam menjual barang yang setara harga dengan kualitas yang diberikan kepada konsumen. Berbeda ketika berbelanja di pasar modern, maka harga yang ditawarkan adalah harga pasti. Nilai kepuasan konsumen (CSI) pada variabel produk adalah $83 \%$ yang tergolong dalam kategori konsumen puas.

Tabel 4. Analisis Perhitungan Nilai CSI Variabel Place

\begin{tabular}{ccccc} 
Atribut & & WF & MSS & WS \\
& & & & \\
& & $(3)=$ & & $(5)=$ \\
$(1)$ & $(2)$ & $(2) /$ total & $(4)$ & $(3 \times 4$ \\
& & & & ) \\
\hline Ketersediaan & 4,60 & 0,59 & 4,20 & 2,50 \\
Identitas & 3,13 & 0,41 & 1,93 & 0,78 \\
Total & 7,73 & & & 3,28 \\
Nilai CSI & & & & $66 \%$ \\
\hline Sumber : Data primer, diolah (2019) &
\end{tabular}

Ketersediaan produk sayuran bagi konsumen menjadi pertimbangan yang cukup besar bagi konsumen dengan nilai 
WS 2,50 pada bauran place. Ketersediaan produk dalam satu lokasi yang sama akan memberi dampak efiensi waktu dan tenaga bagi konsumen. Mayoritas konsumen berbelanja di pasar tradisional tidak hanya satu jenis produk, melainkan untuk memenuhi barang yang saling berkomplemen. Ketersediaan produk akan berpengaruh terhadap kemauan konsumen dalam pembelian ulang dimana hal ini sesuai dengan penelitian Djokic (2016) bahwa ketersediaan produk akan memberikan pengaruh positif pada repurchase intention karena produk yang selalu tersedia menunjukkan kemudahan memperolehnya. Pasar tradisional menyediakan produk sayuran yang dijajakan oleh bermacam pedagang sehingga konsumen memiliki banyak alternatif untuk memilih kebutuhannya pada satu lokasi yang sama. Menurut Kotler dan Keller (2009) salah satu yang mempengaruhi konsumen berbelanja adalah faktor ketersediaan produk. Tidak sedikit konsumen yang kecewa karena barang yang diinginkan tidak tersedia sehingga mengurangi minat pembelian.

Pedagang pasar tradisional khususnya pedagang sayuran sebagian besar tidak memiliki identitas atau plank pada lapaknya. Berbeda dengan pedagang yang memiliki kios cenderung sudah memiliki identitas. Hal ini tidak menjadikan masalah bagi konsumen karena konsumen pasar tradisional tidak memperhatikan atribut identitas kios atau lapak dari pedagang. Konsumen cenderung berbelanja di lokasi yang sudah menjadi langgananya, sehingga yang diingat adalah lokasi berdirinya lapak atau kios bukan identitas planknya. Alasan pedagang tidak menggunakan plank adalah skala usaha yang kecil dimana pedagang biasa menjajakan produknya hanya dalam ukuran $1 \times 1 \mathrm{~m}$ atau $1 \times 2$ meter sehingga tidak memungkinkan untuk menggunakan plank. Selain itu pedagang sayuran yang menggunakan lapak tidak menganggap palank sebagai aspek penting yang bisa meningkatkan pembelian konsumen. Pada penelitian ini nilai WS terkait plank sebagai wadah informasi pedagang tergolong rendah yaitu 0,78 . Nilai kepuasan konsumen pada bauran pemasaran place adalah $66 \%$ yang tegolong dalam kategori konsumen puas.

Tabel 5. Analisis Perhitungan Nilai CSI Variabel Promotion

\begin{tabular}{ccccc}
\hline Atribut & & WF & MSS & WS \\
$(1)$ & $(2)$ & $\begin{array}{c}(3)= \\
(2) / \text { total }\end{array}$ & $(4)$ & $\begin{array}{c}(5)= \\
(3 \times 4)\end{array}$ \\
\hline $\begin{array}{c}\text { Tambahan } \\
\text { produk }\end{array}$ & 4,30 & 0,48 & 3,67 & 1,77 \\
$\begin{array}{c}\text { Potongan } \\
\text { harga }\end{array}$ & 4,58 & 0,52 & 4,05 & 2,09 \\
$\begin{array}{c}\text { Total } \\
\text { Nilai CSI }\end{array}$ & 8,88 & & & 3,86 \\
\hline
\end{tabular}

Sumber : Data primer, diolah (2019)

Terdapat banyak strategi yang dilakukan pedagang dalam menjajakan produknya, termasuk pedagang sayur di pasar tradisional. Jenis promosi yang dilakukan diantaranya adalah memberikan tambahan produk lain bila melakukan pembelian dalam jumlah tertentu atau memberikan potongan harga. Dari hasil penelitian, konsumen lebih menyukai jenis promosi pemberian potongan harga dengan nilai WS 2,09. Sementara pemberian tambahan produk dari pedagang memiliki nilai WS 1,77. Index kepuasan konsumen terhadap variabel promotion di pasar tradisional yaitu $77 \%$ yang tergolong pada kategori puas.

Pemberian hadiah dalam hal ini adalah tamabhan produk kepada konsumen akan menjadi ajang promosi untuk mendapat konsumen baru. Konsumen lama akan menyebarkan informasi positif kepada orang lain sehingga pedagang tidak perlu mengeluarkan biaya promosi yang lebih besar. Pemberian potongan harga akan berpengaruh pada hubungan jangka panjang dengan konsumen yang berarti akan terjadi transaksi yang berkelanjutan antara keduanya.Penelitian Jakpar et al., (2012); Dewi \& Kusumawati (2018) mengatakan bahwa kepuasan pelanggan terhadap kualitas produk diskon didasari pada beberapa atribut yaitu kualitas yang dirasakan, kinerja dan keandalan. 
Tabel 6. Analisis Perhitungan Nilai CSI Variabel People

\begin{tabular}{ccccc}
\hline Atribut & & WF & MSS & WS \\
& & & & \\
$(1)$ & $(2)$ & $\begin{array}{c}(3)= \\
(2) / \text { total }\end{array}$ & $(4)$ & $\begin{array}{c}(5)= \\
(3 \times 4)\end{array}$ \\
\hline Keramahan & 4,85 & 0,52 & 4,10 & 2,12 \\
Kesigapan & 4,52 & 0,48 & 4,12 & 1,99 \\
Total & 9,37 & & & 4,11 \\
Nilai CSI & & & & $82 \%$
\end{tabular}

Sumber : Data primer, diolah (2019)

Pasar tradisional dikenal dengan keramahan yang ditawarkan produsennya kepada konsumen. Pedagang kerap menawarkan produk dengan bahasa lokal yang dibumbui dengan tawaran menarik. Berbeda dengan retail modern dimana konsumen tidak menemukan pedagang yang menawarkan produknya secara langsung, melainkan secara mandiri mencari dan memilih produk tujuannya. Terlebih pedagang yang telah mengenal konsumennya, dalam melayani konsumen sering dibumbui dengan saling bercerita sehingga tidak jarang dapat meningkatkan keeratan sosial antara pedagang dan konsumen.

Nilai WS keramahan pedagang menurut konsumen yaitu 2,12. Mayoritas pedagang menunjukan gestur dan mimik yang ramah dalam melayani konsumen. Sementara konsumen menilai kesigapan pedagang sebesar 1,99. Pedagang pasar tradisional terkadang kurang memperhatikan waktu yang dimiliki konsumen, sehingga konsumen merasa kurang puas. Index kepuasan konsumen variabel people adalah sebesar $82 \%$ yang termasuk dalam kategori sangat puas.

Tabel 7. Analisis Perhitungan Nilai CSI Variabel Proses

\begin{tabular}{ccccc} 
Atribut & & WF & MSS & WS \\
$(1)$ & $(2)$ & $\begin{array}{c}(3)= \\
(2) / \text { tota } \\
1\end{array}$ & $(4)$ & $\begin{array}{c}(5)= \\
(3 \times 4)\end{array}$ \\
\hline $\begin{array}{c}\text { Pembayaran } \\
\begin{array}{c}\text { Fleksibel } \\
\text { Pengemasan } \\
\text { baik }\end{array}\end{array}$ & 4,23 & 0,65 & 2,75 & 1,80 \\
\hline
\end{tabular}

\begin{tabular}{cc}
\hline Total 6,47 & 3,19 \\
Nilai CSI & $64 \%$ \\
\hline Sumber : Data primer, diolah (2019) & \\
Variable processpada & pasar
\end{tabular}
tradisional meliputi pembayaran fleksibel dan pengemasan yang baik. Pembeda pasar tradisonal dengan pasar modern adalah adanya sistem utang piutang antara pedagang dengan konsumen yang sudah menjadi pelanggan lamanya. Dengan azas kepercayaan masih ada beberapa pedagang yang memberikan piutang kepada pelanggannya. Akan tetapi tidak semua pelanggan mendapatkan keistimewaan tersebut, hanya pelanggan yang dirasa sudah dikenal baik oleh padagang.

Nilai WS pemabayaran yang fleksibel di pasar tradisional menurut konsumen yaitu 1,80. Mayoritas konsumen tidak menjadikan pembayaran yang fleksibel atau kemudahan berhutang kepada pedagang sebagai suatu aspek yang perlu dipertimbangkan. Konsumen terbiasa membawa uang cukup untuk berbelanja keperluannya. Hal ini juga dikarenakan konsumen berbelanja sayur tidak terlalu banyak sehingga tidak perlu mengeluarkan uang terlalu besar.

Pengemasan produk sayuran yang dilakukan pedagang pasar tradisional tergolong cukup baik dengan nilai WS 1,39. Pada variabel process kepuasan pelanggan terhadap pengemasan lebih rendah dibanding dengan aspek pembayaran yang fleksibel. Hal ini dikarenakan pedagang terbiasa mencampur segala jenis sayuran pada satu wadah yang sama tanpa memperhatikan aspek lain seperti kualitas produk akan mudah rusak atau kebersihan produk satu dengan yang lain. Index kepuasan konsumen terhadap variabel process yaitu $64 \%$ termasuk dalam kategori puas.Penelitian ini sejalan dengan penelitian Satyo (2013) dimana pelayanan dapat memberi pengaruh terhadap keputusan pembelian dan kepuasan konsumen. 
Tabel 8. Analisis Perhitungan Nilai CSI Variabel Phisically evidence

\begin{tabular}{|c|c|c|c|c|}
\hline Atribut & & WF & MSS & WS \\
\hline (1) & (2) & $\begin{array}{c}(3)= \\
(2) / \text { total }\end{array}$ & (4) & $\begin{array}{l}(5)= \\
(3 \times 4)\end{array}$ \\
\hline \multicolumn{5}{|l|}{ Kebersiha } \\
\hline $\begin{array}{l}\mathrm{n} \\
\text { lingkung } \\
\text { an }\end{array}$ & 4,92 & 0,52 & 3,90 & 2,03 \\
\hline $\begin{array}{l}\text { Produk } \\
\text { rapi }\end{array}$ & 4,52 & 0,48 & 3,95 & 1,89 \\
\hline Total & 9,43 & & & 3,92 \\
\hline Nilai CSI & & & & $78 \%$ \\
\hline
\end{tabular}

Sumber : Data primer, diolah (2019)

Index kepuasan konsumen sayuran pasar tradisional pada variabel phisically evidence adalah $78 \%$ tergolong dalam kriteria puas. Atribut kebersihan lingkungan memiliki nilai WS lebih tinggi yaitu 2,03 dibandingkan dengan atribut kerapihan produk yang memiliki nilai 1,89 . Salah satu ciri pasar tradisional yang dikenal masyarakat luas adalah tingkat kebersihannya. Terlebih ketika hujan masyarakat enggan berbelanja ke pasar karena kondisi yang becek dan menjadi lebih kumuh. Akan tetapi pemerintah kini telah banyak memperhatikan kondisi pasar agar bisa memberikan kenyamanan bagi penggunanya. Pasar tradisional banyak direvitaslisasi menjadi bangunan fisik yang lebih kokoh, bersih dan nyaman. Konsumen sayuran di pasar tradisional Kabupaten Sukoharjo menilai tingkat kebersihan pasar cukup baik. Tidak hanya bangunan yang memiliki wajah baru akan tetapi banyak fasilitas yang telah ditingkatkan pelayanannya seperti ketersediaan toilet dan tempat sampah yang mudah dijangkau.

Sejalan dengan bangunan fisik pasar yang baru, tingkat kesadaran pedagang untuk menjajakan produknya dengan lebih tertata juga meningkat. Konsumen merasa lebih mudah untuk memilih sayur yang segar dan sesuai dengan kebutuhannya baik dilakukan sendiri ataupun dibantu oleh pedagang. Pedagang yang tidak pandai mengatur produk dengan rapi maka akan sulit untuk menarik konsumen. Hal ini dikarenakan produk yang rapi akan memberi daya tarik tersendiri bagi konsumen serta akan lebih menghemat waktu dalam berbelanja karena pedagang mudah menemukan produk yang dicari konsumen. Pertimbangan konsumen dalam membeli tidak hanya terkait kemudahan dalam memperoleh produk namun juga menilai estetika lingkungan pedagang sayuran.

Tabel 9. Analisis Perhitungan Nilai CSI Seluruh Variabel Marketing Mix

\begin{tabular}{lc}
\hline \multicolumn{1}{c}{ Variabel } & Nilai \\
\hline Product & 4,43 \\
Price & 4,13 \\
People & 4,11 \\
Phisically evidence & 3,92 \\
Promotion & 3,86 \\
Place & 3,28 \\
Process & 3,19 \\
$\quad$ Total & 26,92 \\
$\quad$ Rata-rata Total & 3,84 \\
$\quad$ Nilai CSI (Rata-rata total/skala & $77 \%$ \\
max) & \\
\hline Sumber : Data Primer, diolah (2019) &
\end{tabular}

Nilai WS bauran pemasaran pedagang sayuran pasar tradisional bervariasi dengan nilai tertinggi pada variabel Productyaitu 4,43, sementara nilai terendah yaitu variabel Processdengan nilai 3,19.Proses berkaitan dengan fleksibilitas pembayaran serta cara pengamasan produkoleh pedagang yang memberikan kepuasan rendah kepada konsumen. Konsumen terbiasa melakukan transaksi dengan pedagang secara tunai karena kebutuhan sayur yang dibeli tidak terlalu banyak sehingga mengeluarkan biaya yang tidak besar.

Hasil penelitian menunjukkan tingkat kepuasan konsumen terhadap kinerja pedagang sayuran di pasar tradisional tergolong dalam kriteria puas dengan nilai CSI 77\%. Konsumen puas dengan sistem pelayanan pedagang sayuran di pasar tradisional yang tetap menjaga kualitas produk serta masih menjunjung nilai sosial.Nilai CSI menunjukkan hasil kepuasan konsumen pada saat ini, akan tetapi pedagang sayuran di pasar tradisional tetap perlu melakukan peningkatan kinerja 
manajemen sehingga kepausan konsumen tetap terjaga bahkan semakin meningkat.

\section{KESIMPULAN DAN SARAN}

Berdasarkan hasil analisis dengan metode CSI, diperoleh hasil bahwa tingkat kepuasan konsumen terhadap pedagang sayuran di pasar tradisional termasuk dalam kategori puas. Urutan variabel yang memberikan kepuasan tertinggi hingga terendah menurut konsumen adalah variabel product, price, people, phisically evidence, promotion, place, dan process. Kepuasan konsumen dapat ditingkatkan dengan perbaikan kinerja oleh pedagang serta intervensi pemerintah yang memberi kebijakan dan mensosialisasikan kepada pemangku kepentingan.

\section{DAFTAR PUSTAKA}

Al-Tit, A. 2015. The Effect of Service and Food Quality on Customer Satisfaction and Hence Customer Retention. Asian Social Science. Vol.11(23), 129-139.

Arifin, S. \&Yusof, J. 2016. Factors InfluencingPerceived Quality and Repurchase Intention TowardsGreen Products. Procedia Economics and Finance. Vol. 37,391-396.

Ali, M., Purwanti, S., \& Hidayati, S. (2019). Intercropping System for Growth and Yield in Local Varieties of Madura. Agricultural Science, 3(1), 22-30.

BMKG. 2017. Buletin Pemantauan Ketahanan Pangan Indonesia - Edisi Khusus Tren Konsumsi dan Produksi Buah dan Sayur. Vol.8

Baliwati, Y. F., Ali K.\& Caroline M.D. 2004. Pengantar Pangan dan Gizi. Jakarta. PT. Penebar Swadaya.

Dewi, I.K.\& Kusumawati, A. 2018. Pengaruh Diskon Terhadap Keputusan Pembelian dan Kepuasan Pelanggan Bisnis Online. Jurnal Administrasi Bisnis. Vol.56 (1) : 155-163.

Djokic, N. 2016. The Effect of Inventory Level onProduct Availability and Sale. International Journal ofRetail and
Distribution Management. Vol.25(2), 221-234.

Ghezelbash, S. 2017. Evaluating The Impact ofPromotion Price, Product Quality, Service Quality,Customer Satisfaction and Repeating PruchaseIncentives (Case Study: Amiran Chain Stores).Journal of Internet Banking and Commerce. Vol.22(8), 1-17.

Jakpar, S., Na, A.G.S., Johari, A. \& Myint, K.T. 2012. Examing the Product Quality Attributes that Influences Customer Satisfaction Most When the Price was Discount. International Journal of Business and Social Science. Vol.3 (23) : 221-236.

Kartikasari, R.D. 2018. Level of Customer Satisfaction Towards Marketing Mix in Indonesian Traditional Market. Agro Ekonomi. Vol. 29 (2) : 218-230.

Kotler, P.\& Keller, K. 2009. ManajemenPemasaran.GramediaPustaka Utama.Jakarta

Mubyarto.

1989. PengantarEkonomiPertanian. Pustaka LP3ES Indonesia.Jakarta.

Musayana., Suyadi, B. \& Suharso, P. 2017. Kepuasan Konsumen di Pasar Mimbaan Kecamatan Panji Kabupaten Situbondo. Jurnal Pendidikan Ekonomi. Vol.11 (2) : 76-81.

Pakaya, D. 2014. Peranan Vitamin C Pada Kulit. Jurnal Ilmiah Kedokteran. Vol.1(2), 45-54.

Satyo, S. 2013. Pengaruh Diskon Harga, Merk Produk, dan Layanan Pelanggan terhadap Keputusan Pembelian Garmen. Jurnal Ilmu dan Riset Manajemen. Vol.2 (8) :119.

Sugiyono. 2012. Metode Penelitian Bisnis (pendekatan kuantitatif, kualitatif dan $R \& D)$. Alfabeta. Bandung.

Suryani \& Hendryadi. 2015. Metode Riset Kuantitatif : Teori dan Aplikasi pada Penelitian Bidang Manajemen dan Ekonomi Islam. Edisi Pertama.Prenadamedia Group.Jakarta.

Tjiptono, F. 2008. Strategi Pemasaran. Penertbit Andi. Yogyakarta.

Tjiptono, F. \&Chandra, G. 2005. Service, Quality, andSatisfaction. Penertbit Andi. Yogyakart 